\title{
Article \\ Aesthetics as a Habit: Between Constraints and Freedom, Nudges and Creativity
}

Mariagrazia Portera

check for

updates

Citation: Portera, M. Aesthetics as a

Habit: Between Constraints and

Freedom, Nudges and Creativity.

Philosophies 2022, 7, 24. https://

doi.org/10.3390/philosophies7020024

Academic Editor: Fabrizio Desideri

Received: 12 January 2022

Accepted: 28 February 2022

Published: 2 March 2022

Publisher's Note: MDPI stays neutral with regard to jurisdictional claims in published maps and institutional affiliations.

Copyright: (C) 2022 by the author. Licensee MDPI, Basel, Switzerland. This article is an open access article distributed under the terms and conditions of the Creative Commons Attribution (CC BY) license (https:// creativecommons.org/licenses/by/ $4.0 /)$.
Department of Humanities and Philosophy, University of Florence, 50121 Florence, Italy; mariagrazia.portera@unifi.it

\begin{abstract}
This paper is a preliminary attempt to bring to the fore some questions and issues regarding the role of habits in aesthetics. Indeed, much attention has recently been given to habits across a wide range of fields of inquiry: philosophers turn to the concept to investigate its significance to the historical development of Western thought; neuroscientists look into the role that habits play in the functioning of the human mind and identify the neural and psychological underpinnings of habitual behavior; anthropologists, political scientists and sociologists tap into habits as a key notion to explain social dynamics and collective behavior. For all of these waves that the notion has made in other parts of the humanities and social sciences, there have been so far, however, only a few sustained discussions of habits in conjunction with aesthetics. What is the role of habits in aesthetic experience? How do habits influence and regulate artistic creative processes?
\end{abstract}

Keywords: habit; nudge; aestheticization

\section{Habits in Aesthetics}

Much attention has recently been given to habits across a wide range of fields of inquiry: philosophers turn to the concept to investigate its significance to the historical development of Western thought [1-3]; neuroscientists look into the role that habits play in the functioning of the human mind and identify the neural and psychological underpinnings of habitual behavior [4]; anthropologists, political scientists and sociologists tap into habits as a key notion to explain social dynamics and collective behavior [5]. It is a matter of fact that habits pervade our social and mental life to a great extent [6]: "during much of our waking lives, we act according to our habits, from the time we rise and go through our morning routines until we fall asleep", writes neuroscientist Ann Graybiel [4] (p. 360). This centrality of habits to the human individual and social life is notoriously a key point in William James' theory of human behavior. As he states, "when we look at living creatures from an outward point of view, one of the first things that strikes us is that they are bundles of habits" [7] (p. 104).

Carlisle [2] points out that "habit" — a word coming etymologically from the Latin "habitus" ("habeo", to have), which is in turn a calque of the Greek "hèxis" (from "èchein", to have, "to hold a form through time")—designates a genuinely interdisciplinary concept, extensively used in botany, mineralogy, zoology, and of course anthropology and the human and social sciences. As she puts it, "mineralogists refer to the habits of crystals; botanists to the habits of plants; of course, animals, including humans, have habits-and in each case, "habit" means a shape or pattern of growth [ . . ]. Habits are the "way" in which [ ... ] an all-encompassing unity expresses or manifests itself in diverse forms of life" [2] (p. 105).

This paper, which is a preliminary attempt to bring to the fore some questions and issues regarding the role of habits in aesthetics, relies on a relevant premise: for all of the waves that the notion of habit has made over the last few years in other parts of the humanities and social sciences (philosophy, sociology, cognitive sciences, anthropology, 
history of philosophy, and so on), there have so far only been a few sustained discussions of habits in conjunction with aesthetics.

This is particularly striking (and regrettable), since asking about habits and the human aesthetic indeed allows us to relaunch from a different, intriguing perspective some of the most fundamental questions of the discipline: Are we, as human beings, homines aesthetici already at birth or, to the contrary, is the aesthetic something that we have to develop-or to get habituated to-over time? What is the role of habits in creative processes? It is frequently said that, in order to make authentic art, artists must be able to go beyond the obvious, the "already known", must get rid of old habits and bring about something unexpected. However, it is also true that, against any idea of a "creatio ex nihilo", the "standard protocol" for artists (be they poets, musicians, dancers etc.) in order to become able to produce their pieces of art is-almost without exception-that they go through lengthy and arduous periods of apprenticeship. This is precisely with the aim of "accustoming", "habituating" the body - and mind - for the emergence of the new. Nothing authentically new can happen unless one has prepared-and habituated — herself to its arrival. Even artistic improvisers can improvise only once they have embodied a wide series of cultural, technical, social, material constraints, and it is precisely because of and within these constraints that space for improvisation opens up [8].

The same is true, of course, if we consider the "receptive" side of the aesthetic story. How do we learn to prefer certain things over others? How do we learn to behave "aesthetically" at all-making judgements, having aesthetic experiences, formulating preferences? Here again, the history of the arts (literature, music, poetry ... ) is rich in anecdotes and stories about artists producing works "too far ahead" of their times, i.e., for which a suitable public, which means a public endowed with suitable habits of aesthetic appreciation, is yet to come.

I shall divide the paper into three sections: in the first one, relying on the work of Walter Benjamin, I show that, although habits have always played a pivotal role both in aesthetic fruition and in aesthetic-artistic production, contemporary aesthetics, due to a series of distinctive features and characteristics of which I introduce and discuss in Section 2, make habits today even more crucial and relevant than in the past; in the second section (Section 3), I suggest that we adopt the notion of the nudge to make sense of today's aesthetic experience; the nudge theory is a useful tool to bring to the fore the extent to which contemporary aesthetics predetermines the viewer's (habitual) response to aesthetically relevant objects and phenomena, while at the same time providing the viewer with an illusion of "freedom of choice"; in the third and final section (Section 4), I sketch out very rapidly some possible directions for a new, much-needed theory of "aesthetic habits", tapping into some remarks taken from Friedrich Nietzsche's Gay Science.

\section{Interesting Times for Aesthetics}

In his The Work of Art in the Age of Mechanical Reproduction (1936), while discussing the deterioration of the "aura", Walter Benjamin writes, in the frame of some reflections on architecture as a form of art:

Buildings are received in a twofold manner: by use and by perception—or rather, by touch and sight. Such appropriation cannot be understood in terms of the attentive concentration of a tourist before a famous building. On the tactile side, there is no counterpart to contemplation on the optical side. Tactile appropriation is accomplished not so much by attention as by habit. As regards architecture, habit determines to a large extent even optical reception. The latter, too, occurs much less through rapt attention than by noticing the object in incidental fashion. This mode of appropriation, developed with reference to architecture, in certain circumstances acquires canonical value. For the tasks which face the human apparatus of perception at the turning points of history cannot be solved by optical means, that is, by contemplation, alone. They are mastered gradually by habit. [9] 
In these very well-known remarks, Benjamin retrieves, among others, a distinction between the optic and the haptic, or the optical and the tactile, that had already been put forward by Aloïs Riegl in his 1901 masterpiece Late Roman Art Industry. Benjamin makes here two main points: first, that "at the turning points of history" the human apparatus of perception is confronted with new, unprecedented tasks; second, that these new, unprecedented perceptual tasks cannot be solved by the optic apparatus or by contemplation alone. Rather, the tactile dimension - the haptic — and, more specifically and strictly related to the haptic, the habitual dimension is also required. In certain circumstances, indeed, this habitual mode of appropriation acquires even canonical value. But what are these "circumstances"? In what sense, according to Benjamin, do habits become one of the decisive factors (or, perhaps, the most decisive one) in the early 20th century's aesthetic experience? And, moreover, what makes today's aesthetic experience different than the experience of viewers throughout the history of art and the history of aesthetics, or even different than the experience of the viewers that Benjamin described in his time?

While writing his essay, Benjamin notoriously had in mind the unprecedented growth of technology, the precision, pervasivity and adaptability that the techniques of mechanical reproduction of works of art had already attained in the early 20th century. He tried, therefore, to understand the effects and consequences of such a matter of fact on aesthetic experience. As is known, while testifying to the deterioration of the "aura", i.e., to the decline or dissolution of a purely contemplative aesthetic fruition due to the more and more widespread use of techniques of mechanical reproduction, Benjamin also recognized in this decline the possibility for a general emancipation of the aesthetic viewer; as he puts it, the promise of a "politicization of the art" [10]. The habitual mode of appropriation, in this sense, is not only (or not primarily) a detrimental effect of the dissolution of the aura, but also the starting point for potentially new ways of experiencing.

Now, things have obviously changed (and massively) in the aesthetic domain since the first appearance of The Work of Art in the Age of Mechanical Reproduction. However, Benjamin's remarks in that essay are still today a valuable lens through which we can look at and better understand aesthetic experience.

Today, mechanical and (even more) digital technologies have reached a standard of specialization and effectiveness in (re-)producing artworks which would have been simply impossible only ten or twenty years ago. Social media, augmented reality, virtual devices and virtual bodies - which are hybrids existing only in the interaction between a computational text and a human body endowed with technological prostheses-have reconfigured our idea of what an aesthetic experience is [11].

Along with this, aesthetics as a philosophical discipline, after restricting itself for a long time to questions concerning the (higher) arts, flourishes today well beyond the boundaries of what is traditionally considered "artistic". Indeed, the current usage of the word "aesthetic" gives evidence to this movement: it is used, today, more frequently outside of than within the artistic sphere, to indicate a peculiar quality ("aesthetic quality") of lifestyle, general entertainment, media communication, etc. Philosophers call this "global aestheticization": the idea, generally speaking, that the aesthetic dimension has today relevance to any aspect of human life, and (at least under certain respects) has a priority over other values such as ethical, religious, and cultural ones. ${ }^{1}$

Global aestheticization and technological hyper-medialization have become an even more distinctive feature of the aesthetic due to the global pandemic that we are all currently facing, which has changed every aspect of human life as we knew it [15]. Through the mediation of a digital screen, we have been forced during the pandemic to learn new ways of making aesthetic experiences (digital theatre performances, virtual tours in museums and art galleries, online music concerts ... ), although this seems to have led (this, at least, is the first impression ... ) to a condition which is the reversal of the situation predicted by Benjamin in his The Work of Art: A dilation of the optical, instead of a hybrid between optical and haptic (or even instead of a priority of the haptic) (see [15]). 
Notwithstanding these differences, I suggest, here, that we stick to Benjamin's point: in today's aesthetics, as it was for him in the early 20th century, habits acquire canonical value. But what does this statement mean? There are two possible ways for making sense of the current centrality of habits: A negative way and a positive one. This duplicity of interpretation, I argue, has always been intrinsic to habits.

As Carlisle has shown, indeed, if we look at the history of European philosophy, two lines of interpretation emerge, as far as the notion of habit is concerned: According to the first, «habit is an obstacle to reflection and a threat to freedom. Insofar as we think and act out of habit, we are unable to know ourselves or reflect critically on the world [ ... ]. According to the second interpretation, habit is an indispensable part of life: it not only brings order, consistency, and order to our ever-changing experiences, but also allows us to be creative and free» [1] (p. 3). To put it differently, European philosophers, starting at least with Aristotle, have considered habits either as a curse (Spinoza, Kant, etc.) or as a blessing (Aristotle, Hume, Dewey, etc.). Aesthetic habits, in this respect, are no exception. In the following section, I shall consider the (potentially) "negative" side of habits. In other words, capitalizing on a concept of recent coinage taken from the field of behavioral economics, I shall ask: what is an "aesthetic nudge"?

\section{Nudges and Cerulean Sweaters}

Introduced by the American economist and Nobel laureate Richard H. Thaler, together with the Harvard legal scholar Cass R. Sunstein in the bestseller Nudge. Improving Decisions about Health, Wealth, and Happiness [16] and further developed by David Halpern in his Inside the Nudge Unit. How Small Change Can Make a Big Difference [17], the concept of the "nudge" is now a common term in behavioral economics, political theory and behavioral sciences.

In short, the main idea with the nudge theory is to promote change in habitual behavior through positive reinforcement and indirect ecological cues, i.e., by making minimal modifications to the architecture of the environments in which people live and move. Although Thaler and Sunstein do not frequently use the expression "habit", it is precisely at the transformation of individual habits (of consumption) that their theory aims.

The political relevance of the concept of the nudge is high. "Nudge Units" have been created over the last few years by governments and institutions both in North America and Western Europe to encourage-for example-healthy food choices, to increase the amount of time dedicated daily to physical exercise, to boost positive attitudes to savings, or to promote more sustainable behaviors. Cass R. Sunstein served as a nudge advisor during the Barack Obama administration in the United States, while Richard H. Thaler was a member of the United Kingdom's Behavioral Insights Team, and contributed to setting up a Nudge Unit during the government chaired by David Cameron.

Sunstein and Thaler gives the following definition of the "nudge": A nudge is not an imposition but rather "any aspect of the choice architecture that alters people's behavior in a predictable way without forbidding any options or significantly changing their economic incentives. To count as a mere nudge, the intervention must be easy and cheap to avoid. Nudges are not mandates." [16] (p. 6). For instance, a nudge (and not an explicit prohibition) is at work when-to encourage the purchase and consumption of healthy food at a school cafeteria-food is arranged so that vegetables and fruits benefit of the maximum of visibility (eye level), while sweets and snacks are more difficult to pick up by students. The physical environment is intentionally modified, and a change in behavioral habits follows (or should follow) as a consequence: the nudge is, by all means, an ecological-environmental concept.

It is worth stressing that this idea of the ecological nature of nudges and, related to this, of the (only) indirect, environmentally mediated modifiability of habits, was already very well established in John Dewey's works. As we can read in Dewey's Human nature and conduct [18] (pp. 21-22):

Our individual habits are links in forming the endless chain of humanity. Their significance depends upon the environment inherited from our forerunners, and it is enhanced as we foresee the fruits of our labors in the world in which our 
successors live. [ ... ] We can retain and transmit our own heritage only by constant remaking of our own environment. [ ... ] We may desire abolition of war, industrial justice, greater equality of opportunity for all. But no amount of preaching good will or the golden rule or cultivation of sentiments of love and equity will accomplish the results. There must be change in objective arrangements and institutions. We must work on the environment not merely on the hearts of men. To think otherwise is to suppose that flowers can be raised in a desert or motor cars run in a jungle. Both things can happen and without a miracle. But only by first changing the jungle and desert. (My italics)

Going back to Thaler and Sunstein, the obvious premise of their work on nudges is a radical critique of the idea of homo economicus, as this concept has been put forward by (neo)-classical economists under the guidance of Adam Smith's thought. Instead of considering socio-economic agents as purely rational subjects always seeking for utility maximization, and free from passions, distractions or uncertainty, Thaler and Sunstein commit themselves to a model of bounded rationality, in which erratic preferences and beliefs, psychological inclinations, arational emotions and cognitive biases play a relevant (perhaps the most relevant) role. Thaler and Sunstein's nudge-based perspective has been characterized (by the authors themselves) as a sort of "libertarian paternalism", an apparently paradoxical expression which brings to the fore two main points: firstly, that in Thaler and Sunstein's view, socio-economic agents are all inevitably exposed to mistakes, missteps and misunderstandings in their decision-making processes ("bounded rationality"), which implies that they must be "guided for the best". Here, "paternalism" emerges. Secondly, that the use of nudges in decision-making processes never affects or threatens, at least not directly, an agents' freedom, since agents can always and effortlessly take a step back from the nudging architecture; here, the "libertarian" side of the theory is presented.

The role played by an agents' freedom in Thaler and Sunstein's theory deserves further discussion. In what sense is the subject exposed to nudges always free to avoid them or, more precisely, to what extent is the agent's freedom preserved even when he follows a nudge? Richard Thaler, in the preface to David Halpern's book Inside the Nudge Unit, which takes further some of the results of Thaler and Sunstein's 2008 theory, writes: "the idea of the book was that it was possible to use the results of social and behavioral sciences to help people achieve their goals [ ... ] without requiring anyone to do anything, without anyone doing anything" [17] (p. 7); see also [5]. Let us dwell for a moment on the final part of this quotation: "without requiring anyone to do nothing, without anyone doing anything", Thaler writes, which suggests that he has in mind an idea of freedom that has more to do with that of "inertia", the inertia of a consumer devoid of inclinations, strong motivations and firm beliefs, than with that of true freedom. In a word, no authentic freedom but rather only an appearance or guise of it.

Now, let us try to apply Thaler and Sunstein's ideas to contemporary aesthetics.

I shall restrict myself to one (rather well-known) example, taken from the world of fashion or, to be more precise, from a famous film on the world of fashion. I am referring to the relatively recent "The Devil Wears Prada", a 2006 American comedy-drama film directed by David Frankel, produced by Wendy Finerman and starring actresses Meryl Streep (as Miranda Priestly, a bossy fashion magazine editor) and Anne Hathaway (as Andrea Sachs, a brilliant graduate, without any experience in the world of fashion, who ends up with a job as Miranda's assistant). There is an intriguing scene, in the movie, in which Miranda and Andrea have a conversation on the fashion industry and particularly on consumers' freedom of choice.

It has been argued that Miranda's point of view is far from an appropriate representation of today's state-of-the-art climate in contemporary fashion, in which top-down processes (i.e., choices made by fashion designers) intertwine intimately with bottom-up dynamics, (i.e., choices made autonomously by consumers, particularly through informal channels such as social media). What interests me most in the scene, in any case, is Mi- 
randa's idea of "consumers' illusion of freedom"; she argues that the fashion (aesthetic) niche is populated with nudges, although consumers (such as Andrea, in the example) are usually not aware of them.

Here is the transcript of the scene. Miranda and Andrea are both in Miranda's office; the latter is chastising her assistant for assuming that there is no relevant difference between two almost identical blue belts. Andrea, says Miranda, thinks of herself as a too-smartperson to care about fashion, and a person that, through her disinterested attitude, wants to underline her freedom of choice and autonomy:

MIRANDA: You ... go to your closet, and you select ... I don't know, that lumpy blue sweater for instance, because you're trying to tell the world that you take yourself too seriously to care about what you put on your back, but what you don't know is that that sweater is not just blue, it's not turquoise, it's not lapis, it's actually cerulean. You're also blithely unaware of the fact that, in 2002, Oscar de la Renta did a collection of cerulean gowns [ ... ]. And then cerulean quickly showed up in the collections of eight different designers. Then it filtered down through the department stores, and then trickled on down into some tragic casual corner where you, no doubt, fished it out of some clearance bin. [ . . ] It's sort of comical how you think that you've made a choice that exempts you from the fashion industry, when in fact, you're wearing a sweater that was selected for you by the people in this room ... from a pile of "stuff".

Andrea thinks that she has made "a choice that exempts her from the fashion industry", as if she were free, fully capable of self-determination; she fishes her pullover out of a casual corner without being aware of the fact that that pullover (through a complicated series of choices made by others) had been put on display exactly in that corner with the purpose of attracting people like her. This is an example of physical, "architectural" nudge: A small change in objective arrangements with the aim of altering people's habitual behavior "in a predictable way without forbidding any options or significantly changing their economic incentives".

Far from considering these few lines as an exhaustive representation of how the fashion industry works today (see, for a philosophical perspective, [19]), I am using them to raise the following questions: not only in fashion, but also in more traditional contexts such as art galleries, museum exhibitions, theater and dance performances, etc., is it not true that this very same "appearance of freedom" characterizes most of today's aesthetic experiences? Within environments accurately arranged to trigger (or "afford", to recall Gibson's affordances) certain kinds of aesthetic response instead of others, perceivers just have the impression to feel "freely" and unconstrained, but in fact what they feel is nothing more than what others have already felt (and arranged in such a way that we could feel the same). It seems that this is what generally happens to us, homines aesthetici, and to our habits, embedded as we are today within market capitalism and institutional systems. As Gilles Lipovetsky and Jean Serroy have written, we live in the "artistic capitalism" era, "we are all consumers of beauty", but the beauty we consume is not what we have autonomously chosen (however persuaded we might be of our freedom of choice), rather what others have chosen for us with the aim of altering and orienting our aesthetic habits. [20].

\section{4. (Brief) Aesthetic Habits}

What, then, in such a scenario? Is there any residual space for freedom and selfdetermination in aesthetics? Is Kant's "free play of imagination and intellect", as the distinctive feature of aesthetic experience and aesthetic judgement (this is what we read in Kant's Critique of the Power of Judgement, 1790) no more a viable option for the human aesthetic in our times?

I do not think that the "aesthetic nudge" is the conclusive word about today's aesthetic (or anesthetized) experience and, moreover, I do not think that human habits-and human aesthetic habits in particular-should be all understood in terms of nudging processes. As already mentioned [1], habit can form an obstacle to reflection and a threat to freedom, but 
is also an indispensable resource to bring order and consistency to our lives, making us creative and free. Although developing a theory in detail about the constructive role of habits in aesthetics, including today's aestheticized experience, falls well outside the scope and limits of this paper, this is the direction in which I go. I restrict myself to a single quote, taken from Friedrich Nietzsche's The Gay Science. Nietzsche, in this journey towards a constructive and "positive" sense of habits in aesthetics, has indeed already paved the way:

I love brief habits and consider them invaluable means for getting to know many things and states down to the bottom of their sweetnesses and bitternesses [ ... ]. I always believe this will give me lasting satisfaction-even brief habits have this faith of passion, this faith in eternity - and that I am to be envied for having found and recognized it, and now it nourishes me at noon and in the evening and spreads a deep contentment around itself and into me, so that I desire nothing else, without having to compare, despise, or hate. And one day its time is up; the good thing parts from me, not as something that now disgusts me but peacefully and sated with me, as I with it, and as if we ought to be grateful to each other and so shake hands to say farewell. And already the new waits at the door along with my faith—the indestructible fool and sage!- that this new thing will be the right thing, the last right thing. This happens to me with dishes, thoughts, people, cities, poems, music, doctrines, daily schedules, and ways of living [ ... ]. To me the most intolerable, the truly terrible, would of course be a life entirely without habits.

"To me the most intolerable, the truly terrible, would of course be a life entirely without habits": the challenge that Nietzsche invites us to take up is to develop a comprehensive theory of (aesthetic) habits; not enduring, but rather brief; not individual, but rather participative and relational; not devoid of emotions, but rather passionate, and able to give us "lasting satisfaction", as if, in their brevity, they were eternal [21]. The challenge for a new theory of aesthetic habits, as the intriguing cornerstone of a new aesthetic theory for our digital, technological, "artistic-capitalistic" times, is on.

Funding: This research received no external funding.

Conflicts of Interest: The author declares no conflict of interest.

\section{Notes}

See, on the concept of aestheticization, among the many contributions on the topic: Y. Michaud, "L'art à l'état gazeux" [12]; W. Welsch, "Aestheticization Processes. Phenomena, Distinctions and Pro-spects" [13]; H.K. Nielsen, "Totalizing Aesthetics? Aesthetic Theory and the Aestheticization of Every-day Life" [14].

\section{References}

1. Carlisle, C. On Habit; Routledge: London, UK, 2014.

2. Carlisle, C. Habit, practice, grace: Towards a philosophy of religious life. In New Models of Religious Understanding; Ellis, F., Ed.; Oxford University Press: Oxford, UK, 2018; pp. 97-115.

3. Sparrow, T.; Hutchinson, A. (Eds.) A History of Habit: From Aristotle to Bourdieu; Lexington Books: Lanham, MD, USA, 2013.

4. Graybiel, A.M. Habits, Rituals, and the Evaluative Brain. Annu. Rev. Neurosci. 2008, 31, 359-387. [CrossRef] [PubMed]

5. Pedwell, C. Habit and the politics of social change: A comparison of nudge theory and pragmatist philosophy. Body Soc. 2017, 23, 59-94. [CrossRef]

6. Bargh, J.A. The automaticity of everyday life. In Advances in Social Cognition; Wyer, R.S., Ed.; Lawrence Erlbaum Associates Inc.: Mahwah, NJ, USA, 1997; pp. 1-61.

7. James, W. The Principles of Psychology; Dover Publications Inc.: New York, NY, USA, 1890.

8. Bertinetto, A.; Bertram, G. We make Up the Rules As we Go Along: Improvisation As an Essential Aspect of Human Practices? Open Philos. 2020, 3, 202-221. [CrossRef]

9. Benjamin, W. The Work of Art in the Age of Mechanical Reproduction. In The Work of Art in the Age of Technological Reproducibility and Other Writings on Social Media; Jennings, M.W., Doherty, B., Levin, T.Y., Eds.; The Belknap Press of Harvard University: Cambridge, MA, USA, 2008.

10. Desideri, F.; Montanelli, M. L'opera D'arte Nell'epoca della sua Riproducibilità Tecnica. Edizione Integrale Comprensiva delle Cinque Stesure; Donzelli Editore: Bologna, Italy, 2019. 
11. Diodato, R. Aesthetics of the Virtual; State University of New York Press: Albany, NY, USA, 2012.

12. Michaud, Y. L'art à l'état gazeux. In Essai sur le Triomphe de L'esthétique; Hachette: Paris, France, 2003.

13. Welsch, W. Aestheticization Processes. Phenomena, Distinctions and Prospects. Theory Cult. Soc. 1996, 13, 1-24. [CrossRef]

14. Nielsen, H.K. Totalizing Aesthetics? Aesthetic Theory and the Aestheticization of Everyday Life. Nordisk Estetisk Tidskrift 2005, $32,60-75$.

15. Desideri, F.; Zingaro, V.; Portera, M. The Work of Art in the Age of Its Sanitized Fruition. Notes for a Pandemic Aesthetics. Paragrana 2021, 30, 203-213. [CrossRef]

16. Thaler, H.; Sunstein, C.R. Nudge. Improving Decisions about Health, Wealth, and Happiness; Yale University Press: New Haven, CT, USA; London, UK, 2008.

17. Halpern, D. Inside the Nudge Unit. How Small Changes Can Make a Big Difference; Ebury: London, UK, 2015.

18. Dewey, J. Human Nature and Conduct. An Introduction to Social Psychology. Holt \& Co.: New York, NY, USA, 1922.

19. Matteucci, G.; Marino, S. Philosophical Perspectives on Fashion; Bloomsburyl: London, UK, 2016.

20. Lipovetsky, G.; Serroy, J. L'esthétisation du Monde. Vivre à l'âge du Capitalisme Artiste; Gallimard: Paris, France, 2013.

21. Nietzsche, F. The Gay Science; Vintage Books: New York, NY, USA, 1974. 